\title{
Incidence and risk factors for insufficient endometrial tissue from endometrial sampling
}

This article was published in the following Dove Press journal: International Journal of Women's Health

\author{
Apiwat Aue-aungkul \\ Pilaiwan Kleebkaow \\ Chumnan Kietpeerakool \\ Department of Obstetrics and \\ Gynecology, Faculty of Medicine, \\ Khon Kaen University, Khon Kaen, \\ Thailand
}

Correspondence: Apiwat Aue-aungkul Department of Obstetrics and Gynecology, Faculty of Medicine, Khon Kaen University, I 23 Mittraphap Highway, Muang Khon Kaen, Khon Kaen 40002, Thailand

Tel +6643363030

Email apiwat_ant@hotmail.com
Objective: To assess the incidence of and factors that predict insufficient tissue after endometrial sampling.

Methods: This study reviewed the records of women undergoing endometrial sampling at Khon Kaen University's Srinagarind Hospital between June 2014 and June 2015. It excluded cases in which the device could not be inserted into the uterine cavity due to pain intolerance or equipment failure. The criterion for diagnosing insufficient endometrial tissue was a lack of any intact tissue fragments containing both glands and stroma.

Results: Medical records of 233 women were reviewed. Insufficient tissue following endometrial sampling was noted in 67 cases $(28.8 \%$; 95\% confidence interval $[\mathrm{CI}]=23.0-35.0)$. Histologic results in the remaining 166 women included normal pathological endometrium (121, 51.9\%), endometrial polyps (7, 3.0\%) endometrial hyperplasia (27, 11.6\%), and endometrial cancer $(11,4.7 \%)$. According to multivariable analysis, menopausal status (odds ratio $[\mathrm{OR}]=3.60,95 \% \mathrm{CI}=1.84-7.05$ ) and endometrial thickness of less than $8 \mathrm{~mm}(\mathrm{OR}=3.91,95 \% \mathrm{CI}=1.49-10.21)$ were significant independent predictors for insufficient endometrial tissue after endometrial sampling.

Conclusion: The incidence of insufficient tissue following endometrial sampling was $28.8 \%$. Significant independent factors associated with an increased risk of insufficient tissue were menopausal status and endometrial thickness of less than $8 \mathrm{~mm}$.

Keywords: insufficient endometrial tissue, endometrial sampling, Endocell ${ }^{\circledR}$, sample adequacy, inadequate sampling

\section{Introduction}

Endometrial sampling is a method used to obtain endometrial tissue in order to histologically examine women who have abnormal uterine bleeding. ${ }^{1}$ This procedure is commonly performed to look for significant endometrial pathologies, including endometrial hyperplasia and endometrial carcinoma, in women who have an abnormally thick endometrium on imaging, atypical glandular cells on cervical smear, or postmenopausal bleeding., ${ }^{2,3}$

Previous studies have indicated that the performance of endometrial sampling is as good as those of dilatation and curettage (D\&C) or manual vacuum aspiration. ${ }^{4,5}$ In cases of postmenopausal bleeding, endometrial sampling has been shown to have a sensitivity of $90 \%$ and specificity of $99 \%-100 \%$ for diagnosing endometrial hyperplasia or endometrial cancer with D\&C or hysteroscopy with biopsy as a reference standard. ${ }^{6}$ A previous systematic review found moderate agreement with regard to tumor grade between endometrial sampling and final pathology from hysterectomy.

The disadvantage of endometrial sampling relates to the small volume of endometrial tissue obtained. Endometrial sampling yields insufficient tissue for definite pathological diagnosis in $6 \%-33 \%$ of cases. ${ }^{8-13}$ Approximately $6 \%$ of postmenopausal women with 
nondiagnostic specimens after endometrial sampling for abnormal uterine bleeding are subsequently found to have significant endometrial lesions on further evaluation. ${ }^{12,14}$ Therefore, it is necessary to identify patients in whom endometrial sampling may yield insufficient tissue and for whom other endometrial evaluation procedures would be more suitable. The aim of this study is to assess the incidence of and factors that predict insufficient tissue after endometrial sampling.

\section{Methods}

After receiving approval from the Khon Kaen University Ethics Committee for Human Research based on the Declaration of Helsinki and the ICH Good Clinical Practice Guidelines (HE591350), we reviewed the records of women who underwent endometrial sampling as a primary treatment at Khon Kaen University (KKU)'s Srinagarind Hospital, between June 2014 and June 2015. Because this was a retrospective study and data were analyzed anonymously, the need for informed consent was waived by the ethics committee. We excluded cases in which the device could not be inserted into the uterine cavity due to intolerance to pain or equipment failure.

Methods to obtain endometrial tissues for pathology examination in our institution depended on the menopausal status. Endometrial sampling was performed in all premenopausal woman with abnormal uterine bleeding. For postmenopausal women, there were two options, ie, endometrial aspiration or transvaginal ultrasound for endometrial measurement.

All endometrial sampling procedures were performed via Endocell ${ }^{\circledR}$ (disposable endometrial cell sampler tube; CooperSurgical, Inc., Trumbull, CT, USA) requiring only manual suction to extract a sample from the endometrium. This device provides excellent suction using an elastomeric seal piston plunger with an outside diameter of $3.1 \mathrm{~mm}$. All sampling procedures were conducted by the residents in training or members of the gynecology staff. Abstract data included in this study were patient characteristics, indications for endometrial sampling, endometrial thickness by ultrasound (if any), types of operators (gynecology residents vs attending staffs), and detailed pathological reports. Pathological tissue reports were reviewed by a single gynecologic pathologist (PK). The criterion for diagnosis of insufficient endometrial tissue was a lack of any intact tissue fragments containing both glands and stroma. ${ }^{15}$

Descriptive statistics were used for reporting the data. The chi-square and Fisher's exact tests were used to univariately identify factors potentially related to insufficient endometrial tissue samples. Factors with a $P$-value less than 0.20 according to univariate analysis were subjected to multivariate analysis using a logistic model to reveal which were the independent factors. An odds ratio (OR) with a 95\% confidence interval (CI) that did not include unity was considered statistically significant. Statistical analyses were carried out using SPSS version 17.0 (SPSS Inc., Chicago, IL, USA).

\section{Results}

The medical records of 233 women who underwent endometrial sampling were reviewed. Table 1 displays the baseline characteristics of the patients. The mean age of the patients was 48.3 years (range=27-86 years). Transvaginal ultrasound for evaluating endometrial thickness was performed in 108 (46.4\%) women. Endometrial thickness ranged from 1.9 to $53.0 \mathrm{~mm}$.

Insufficient tissue following endometrial sampling was noted in 67 women (a rate of $28.8 \% ; 23.0-35.0$ ). The histologic results of the remaining 166 women included normal pathological endometrium $(121,51.9 \%)$, endometrial polyps (7, 3.0\%), endometrial hyperplasia $(27,11.6 \%)$, and endometrial cancer $(11,4.7 \%)$.

Details regarding endometrial thickness as measured by transvaginal ultrasound are reported in Table 1. Subsequent

Table I Baseline characteristics $(n=233)$

\begin{tabular}{ll}
\hline Characteristics & $\begin{array}{l}\text { Number of } \\
\text { women (\%) }\end{array}$ \\
\hline Age & $213(91.4)$ \\
Younger than 60 years & $20(8.6)$ \\
60 years or older & \\
Parity & $28(12.0)$ \\
$\quad$ Nulliparous & $205(88.0)$ \\
Multiparous & \\
Menopausal status & $162(69.5)$ \\
Premenopause & $71(30.5)$ \\
Postmenopause & \\
Previous vaginal birth & $177(75.9)$ \\
Yes & $56(24.1)$ \\
No & \\
Current hormone use & $55(23.6)$ \\
Yes & $178(76.4)$ \\
No & \\
Types of operator & $192(82.4)$ \\
In-training resident & $4 I(17.6)$ \\
Gynecology staff & \\
Indications for endometrial sampling & $190(81.5)$ \\
Abnormal uterine bleeding & $37(15.9)$ \\
Abnormal glandular cells on cervical smears & $6(2.6)$ \\
Postmenopausal pyometra & \\
Endometrial thickness (cutoff 8 mm) & $59(54.6)$ \\
Less than 8 mm & $49(45.4)$ \\
8 mm or more & \\
\hline
\end{tabular}


management of women with insufficient samples included fractional curettage $(18 ; 26.9 \%)$, re-endometrial biopsy $(5 ; 7.5 \%)$, hysterectomy $(9 ; 13.4 \%)$, and no further management $(35 ; 52.2 \%)$. In the 67 women with insufficient endometrial tissue samples, there is no evidence of endometrial carcinoma development over a median follow-up period of 36 months. Eleven (4.7\%) patients were diagnosed with endometrial carcinoma (one unstaged, four stage IA, two stage IB, two stage II, one stage IIIC1, and one stage IVB).

Eight clinical variables were analyzed, including advanced age, parity, menopausal status, operator, previous vaginal birth, current hormonal use, indications for endometrial sampling, and endometrial thickness, to significantly predict insufficient endometrial tissue among the specimens. Menopausal status, endometrial thickness, and advanced age had $P$-values of less than 0.20 according to univariate analysis. Multivariate analysis was performed using a logistic regression model that included three significant covariates. Only menopausal status ( $\mathrm{OR}=3.60,95 \% \mathrm{CI}=1.84-7.05)$ and endometrial thickness less than $8 \mathrm{~mm}(\mathrm{OR}=3.91,95 \%$ $\mathrm{CI}=1.49-10.21)$ remained statistically significant predictors for insufficient endometrial tissue on disposable endometrial cell sampler tube after this analysis (Table 2).

\section{Discussion}

Insufficient endometrial tissue following endometrial sampling is widely observed in gynecological practices and can often lead to critical problems in clinical management. In this study, we evaluated the magnitude of and factors related to the collection of insufficient endometrial samples. The incidence of insufficient endometrial tissue was $28.8 \%$ (95\% CI=23.0-35.0). A multivariate analysis revealed that postmenopausal status and endometrial thickness less than 8 $\mathrm{mm}$ were significant predictors for insufficient endometrial tissue.

The rate of insufficient tissue following endometrial sampling varies widely in the literature, from $6 \%$ to $33 \%$. This may be due to secondary differences across the studies in terms of sample characteristics, in particular the proportions of menopausal patients, diagnostic criteria for insufficient tissue, and types of provider. ${ }^{8,9,11,12}$

In the present study, postmenopausal women carried a higher risk of insufficient tissue after endometrial sampling $(\mathrm{OR}=3.60,95 \% \mathrm{CI}=1.84-7.05)$, which is in line with the results of previous studies..$^{8,10,11}$ Bakour et $\mathrm{al}^{8}$ reported that menopausal status was associated with insufficient specimen $(\mathrm{OR}=4.49,95 \% \mathrm{CI}=2.49-8.09)$. Williams et $\mathrm{al}^{10}$ found that

Table 2 Factors predicting insufficient endometrial tissue

\begin{tabular}{|c|c|c|c|}
\hline Variables & $\begin{array}{l}\text { Number of } \\
\text { insufficient (\%) }\end{array}$ & $\begin{array}{l}\text { Univariate } \\
P \text {-value }\end{array}$ & $\begin{array}{l}\text { Multivariate } \\
\text { OR }(95 \% \mathrm{Cl})\end{array}$ \\
\hline \multicolumn{4}{|l|}{ Menopausal status } \\
\hline Postmenopause $(n=7 I)$ & $34(47.9)$ & $<0.05$ & $3.60(1.84-7.05)$ \\
\hline Premenopause $(n=162)$ & $33(20.4)$ & & Reference \\
\hline \multicolumn{4}{|l|}{ Endometrial thickness } \\
\hline Less than $8 \mathrm{~mm}(\mathrm{n}=59)$ & $25(42.4)$ & 0.01 & $3.91(1.49-10.21)$ \\
\hline $8 \mathrm{~mm}$ or more $(\mathrm{n}=49)$ & $8(16.3)$ & & Reference \\
\hline \multicolumn{4}{|l|}{ Age } \\
\hline 60 years or older $(n=20)$ & $9(45.0)$ & 0.09 & $0.95(0.32-2.77)$ \\
\hline Younger than 60 years $(n=2 \mid 3)$ & $58(27.2)$ & & Reference \\
\hline \multicolumn{4}{|l|}{ Indications for endometrial sampling } \\
\hline AUB $(n=190)$ & $58(30.5)$ & 0.20 & Variable removed \\
\hline Non-AUB $(n=43)$ & $9(20.9)$ & & \\
\hline \multicolumn{4}{|l|}{ Current hormone use } \\
\hline Yes $(n=55)$ & $13(23.6)$ & 0.34 & Variable removed \\
\hline No $(n=178)$ & $54(30.3)$ & & \\
\hline \multicolumn{4}{|l|}{ Parity } \\
\hline Nulliparity $(\mathrm{n}=28)$ & $10(35.7)$ & 0.38 & Variable removed \\
\hline Multiparity $(n=205)$ & $57(27.8)$ & & \\
\hline \multicolumn{4}{|l|}{ Previous vaginal birth } \\
\hline Yes $(n=177)$ & $53(29.9)$ & 0.47 & Variable removed \\
\hline No $(n=56)$ & $14(25.0)$ & & \\
\hline \multicolumn{4}{|l|}{ Operator } \\
\hline In-training resident $(\mathrm{n}=192)$ & $55(28.6)$ & 0.93 & Variable removed \\
\hline Staff member $(n=4 I)$ & $12(29.2)$ & & \\
\hline
\end{tabular}

Abbreviations: $\mathrm{AUB}$, abnormal uterine bleeding; $\mathrm{OR}$, odds ratio; $\mathrm{Cl}$, confidence interval. 
the rate of adequate tissue after endometrial sampling was $52 \%$ in postmenopausal women, but $92 \%$ in those who were premenopausal. Recently, Xie et $\mathrm{al}^{11}$ confirmed that menopausal status increased the risk of sample inadequacy following endometrial sampling $(\mathrm{OR}=8.324,95 \% \mathrm{CI}=3.79-18.24)$. The higher rate of insufficient tissue after endometrial sampling among postmenopausal women may be due to atrophic changes to the endometrium, which could, in turn, result in less tissue being obtained. ${ }^{16}$

Previous studies have consistently reported an association between endometrial thickness as evaluated by transvaginal ultrasonography and risk of insufficient tissue after subsequent endometrial sampling. . $^{81,17,18}$ However, the cutoff threshold for endometrial thickness has varied across these studies. Bakour et $\mathrm{al}^{8}$ found that endometrial thickness above $5 \mathrm{~mm}$ decreased the risk of insufficient sample on endometrial biopsy $(\mathrm{OR}=0.19,95 \% \mathrm{CI}=0.07-0.53)$. Elsandabesee and Greenwood $^{19}$ stated that there was only a $27 \%$ probability of getting an adequate endometrial sample in women with an endometrial thickness of less than $5 \mathrm{~mm}$, compared to $60 \%$ among those with an endometrial thickness $\geq 5 \mathrm{~mm}$. Visser et al ${ }^{17}$ showed that endometrial thickness $>12 \mathrm{~mm}$ independently decreased the chance of insufficient sampling $(\mathrm{OR}=0.26,95 \% \mathrm{CI}=0.09-0.76)$. Recently, Xie et al ${ }^{11}$ found that an endometrial thickness of less than $7 \mathrm{~mm}$ was significantly associated with sample inadequacy ( $O R=6.74$, 95\% CI=3.04-14.90). In our study, an endometrial thickness of less than $8 \mathrm{~mm}$ according to transvaginal ultrasound increased the risk of inadequate endometrial sampling (OR=3.91, 95\% CI=1.49-10.21).

There has been controversy about the association between advanced age and an adequacy of endometrial samples. ${ }^{8,17,19,20}$ Previous studies noted an approximate 4\% increase in the rate of insufficient tissue after endometrial sampling with each year of increasing age..$^{8,17}$ Kandil et $\mathrm{al}^{20}$ demonstrated that there was a significantly higher rate of insufficient samples among women 60 years and older compared to younger women (14.6\% vs 5.8\%). However, Adambekov et $\mathrm{al}^{18}$ showed that age over 55 years was not associated with inadequate tissue following endometrial sampling $(\mathrm{OR}=1.95$, $95 \% \mathrm{CI}=0.72-5.30$ ). In this study, women 60 years of age and older had a higher rate of insufficient endometrial tissue compared to younger women (45.0\% vs $27.2 \%)$. However, this difference was not statistically significant according to multivariate analysis $(\mathrm{OR}=0.95,95 \% \mathrm{CI}=0.32-2.77)$.

This study found no association between insufficient samples and other reproductive characteristics, such as nulliparity, previous vaginal birth, or current hormonal use, which contrast with the results of previous studies. ${ }^{11,17,19}$ Prolonged use of oral combined contraceptive pills, depomedroxyprogesterone acetate, or menopausal hormonal therapy can cause endometrial atrophy, thus resulting in higher risk of insufficient samples following endometrial sampling. ${ }^{21}$ Additionally, Adambekov et al ${ }^{18}$ reported an increased risk of insufficient tissue after endometrial sampling among women who presented with postmenopausal bleeding when compared to those who underwent endometrial sampling with other indications ( $\mathrm{OR}=7.41$, 95\% CI=2.27-24.14). ${ }^{19}$ However, there was no significant difference between women who had abnormal uterine bleeding and those who presented with other symptoms in terms of the risk of insufficient tissue after endometrial sampling in the present study.

It is debatable whether or not the training level of operator affects the rate of insufficient tissue after endometrial sampling. A recent study showed that the procedure being conducted by a nonphysician provider was associated with an increased risk of sampling failure $(O R=9.15$, 95\% CI=2.49-33.69). ${ }^{19}$ However, this association was not reaffirmed by other studies. ${ }^{11,17}$ In this study, there was no significant association between the type of operator (intraining residents vs staff members) and risk of insufficient endometrial tissue.

In this study, $35(52.2 \%)$ of the 67 women with insufficient endometrial tissue samples did not undergo further endometrial evaluation. Previous studies indicated that approximately $6 \%-7 \%$ of women with insufficient endometrial tissue samples were subsequently found to have atypical endometrial hyperplasia or endometrial cancer. ${ }^{12}$ These findings highlight the importance of further evaluation to ensure exclusion of significant endometrial pathology among women with insufficient endometrial samples.

The main limitation of this study is that, due to its retrospective nature, some information was unavailable. This included sonographic results regarding endometrial thickness and uterine volume, as well as previous failed attempts at endometrial sampling, all of which have been shown to be important factors associated with the risk of insufficient endometrial tissue samples. In addition, the reasons for not performing further diagnostic procedures among women with insufficient samples are unknown. Despite this limitation, the primary strength of the study was that it was conducted in a single institution, where the pathological specimens are reviewed by experienced gynecologic pathologists, and criteria for evaluating the adequacy of tissue are standardized. 


\section{Conclusion}

The incidence of insufficient tissue following endometrial sampling was $28.8 \%$ (23.0-35.0). Significant independent factors associated with an increased risk of insufficient tissue were menopausal status and endometrial thickness less than $8 \mathrm{~mm}$.

\section{Acknowledgment}

Special thanks to Dr Dylan Southard for editing the English version of the manuscript via Publication Clinic, Khon Kaen University, Thailand.

\section{Disclosure}

The authors report no conflicts of interest in this work.

\section{References}

1. du J, Li Y, Lv S, et al. Endometrial sampling devices for early diagnosis of endometrial lesions. J Cancer Res Clin Oncol. 2016;142(12): 2515-2522.

2. Berek JS, Hacker NF. Berek and Hacker's Gynecologic Oncology. 6th ed. Philadelphia, PA: Lippincott Williams \& Wilkins; 2010.

3. Chambers JT, Chambers SK. Endometrial sampling: When? Where? Why? With what? Clin Obstet Gynecol. 1992;35(1):28-39.

4. Tanriverdi HA, Barut A, Gün BD, et al. Is pipelle biopsy really adequate for diagnosing endometrial disease? Med Sci Monit. 2004;10: CR271-CR274.

5. Wanijasombutti $\mathrm{P}$, Imruetaicharoenchok A, Tangitgamol S, et al. Comparison of tissue adequacy for histologic examination from Ipas MVA plus and Wallach Endocell in women with abnormal uterine bleeding. J Obstet Gynaecol Res. 2015;41(8):1246-1254.

6. van Hanegem N, Prins MM, Bongers MY, et al. The accuracy of endometrial sampling in women with postmenopausal bleeding: a systematic review and meta-analysis. Eur J Obstet Gynecol Reprod Biol. 2016;197:147-155

7. Visser NCM, Reijnen C, Massuger L, et al. Accuracy of Endometrial Sampling in Endometrial Carcinoma: A Systematic Review and Metaanalysis. Obstet Gynecol. 2017;130(4):803-813.
8. Bakour SH, Khan KS, Gupta JK. Controlled analysis of factors associated with insufficient sample on outpatient endometrial biopsy. BJOG. 2000;107(10):1312-1314.

9. Gordon SJ, Westgate J. The incidence and management of failed Pipelle sampling in a general outpatient clinic. Aust N Z J Obstet Gynaecol. 1999;39(1):115-118.

10. Williams AR, Brechin S, Porter AJ, Warner P, Critchley HO. Factors affecting adequacy of Pipelle and Tao Brush endometrial sampling. BJOG. 2008;115(8):1028-1036.

11. Xie B, Qian C, Yang B, et al. Risk Factors for Unsuccessful OfficeBased Endometrial Biopsy: A Comparative Study of Office-Based Endometrial Biopsy (Pipelle) and Diagnostic Dilation and Curettage. J Minim Invasive Gynecol. 2018;25(4):724-729.

12. van Doorn $\mathrm{HC}$, Opmeer BC, Burger CW, et al. Inadequate office endometrial sample requires further evaluation in women with postmenopausal bleeding and abnormal ultrasound results. Int J Gynaecol Obstet. 2007;99(2):100-104.

13. Clark TJ, Mann CH, Shah N, et al. Accuracy of outpatient endometrial biopsy in the diagnosis of endometrial cancer: a systematic quantitative review. BJOG. 2002;109(3):313-321.

14. Adwar W, Gadde R, Chitale DA, et al. Management of insufficient endometrial biopsy for women with abnormal uterine bleeding: to further investigate or reassure? Lab Invest. 2016;96:273A.

15. Tanriverdi HA, Barut A, Gün BD, Kaya E. Is pipelle biopsy really adequate for diagnosing endometrial disease? Med Sci Monit. 2004 10(6):271-274.

16. Mccluggage WG. My approach to the interpretation of endometrial biopsies and curettings. J Clin Pathol. 2006;59(8):801-812.

17. Visser NC, Breijer MC, Herman MC, et al. Factors attributing to the failure of endometrial sampling in women with postmenopausal bleeding. Acta Obstet Gynecol Scand. 2013;92(10):1216-1222.

18. Adambekov S, Goughnour SL, Mansuria S, et al. Patient and provider factors associated with endometrial Pipelle sampling failure. Gynecol Oncol. 2017;144(2):324-328.

19. Elsandabesee D, Greenwood P. The performance of Pipelle endometrial sampling in a dedicated postmenopausal bleeding clinic. $J$ Obstet Gynaecol. 2005;25(1):32-34.

20. Kandil D, Yang X, Stock1 T, Liu Y. Clinical outcomes of patients with insufficient sample from endometrial biopsy or curettage. Int J Gynecol Pathol. 2014;33(5):500-506.

21. Deligdisch L. Hormonal pathology of the endometrium. Mod Pathol. 2000;13(3):285.
International Journal of Women's Health

\section{Publish your work in this journal}

The International Journal of Women's Health is an international, peerreviewed open-access journal publishing original research, reports, editorials, reviews and commentaries on all aspects of women's healthcare including gynecology, obstetrics, and breast cancer. The manuscript management system is completely online and includes

\section{Dovepress}

a very quick and fair peer-review system, which is all easy to use. Visit http://www.dovepress.com/testimonials.php to read real quotes from published authors. 